\title{
Evaluation of Vascular Complications in Patients with Type 2 Diabetes Mellitus at a South Indian Tertiary Care Hospital
}

\author{
Silvya Grace B ${ }^{1, *}$, Soma Sundaram I ${ }^{2}$ \\ ${ }^{1}$ PhD Scholar, VELS University, Pallavarum, Chennai, Tamil Nadu, India; \\ ${ }^{2}$ Professor, VELS University, Pallavarum, Chennai, Tamil Nadu, India.
}

\section{ARTICLE INFO: \\ Received: 29 Jan 2021 \\ Accepted: 22 Feb 2021 \\ Published: 28 Feb 2021 \\ Corresponding author * \\ Silvya Grace B, \\ PhD Scholar, VELS University, \\ Pallavarum, Chennai, Tamil \\ Nadu, India. \\ E Mail: silvyagrace@gmail.com}

\begin{abstract}
:
Background: Now a day, globally diabetes is one of the most common chronic noncommunicable diseases globally. In our study to assess, the clinical characteristics and complications in patients with type 2 diabetes mellitus. The main aim of the present study was to evaluate the complications among diabetic patients in different age groups. Methodology: It's a Prospective-observational study, carried out in 9 months at patients attending a tertiary care hospital in Guntur. We enrolled age group between 30- 80 years patients. Results: Out of 215 patients, males were 122 and females were 93 . Above $50 \%$ of patients were diagnosed within the age group of $51-65$ years. About $61 \%$ of patients were having overweight based on BMI ranges and about $63 \%$ of patients were at high risk of HbA1C i.e., $>6 \%$. The mean age was found to be 51-65(50.97\%). Out of all comorbidities, it was found that hypertension $112(52.09 \%)$ was high. The complications associated with diabetes found in the present study were microvascular complications which include microvascular complications, nephropathy $(n=63)$ was high followed by neuropathy $(n=53)$; retinopathy $(n=31)$, and males $(n=108)$ were more prone than females $(n=80)$. Drug therapy was monotherapy $106(49.30 \%)$ and dual therapy $29(13.48 \%)$. Triple therapy $7(3.25 \%)$ usage was less when compared to mono and dual therapy. Conclusion: Based on our study interpretation, the complications of DM are commonly seen in those are having uncontrolled glucose levels. Among microvascular complications, nephropathy was most commonly observed, followed by neuropathy also. Enhancing level of HbA1c and BMI was found to be a more significant correlation with neuropathy in most of the individuals.
\end{abstract}

Keywords: Diabetes mellitus, Coronary artery diseases, Macrovascular, microvascular, nephropathy.

\section{INTRODUCTION}

The ancient time Indian physicians, Sushruta and Charaka (400-500 A.D.) identified the two types, afterward named as Type I and Type II diabetes [1]. Diabetes is fast gaining the status of a potential epidemic in India. Currently, there are an estimated 72.96 million cases of diabetes in the adult population of India [2]. The prevalence in urban areas ranges between $10.9 \%$ and $14.2 \%$ and prevalence in rural India was $3.0-7.8 \%$ among population aged 20 years and above with a much higher prevalence among individuals aged over 50 years [3]. It is predicted that by the year 2030 diabetes mellitus may afflict up to 79.4 million individuals in India, while United States (30.3 million) will also see significant increases in those affected by the disease(4)Two-thirds of individuals with diabetes die of cardiovascular diseases and stroke. Many risk factors increase the chance of high mortality rates $[3,4]$.
The risk of the occurrence of devastating complications of target organs like the eyes, vessels, nerves, and kidneys ultimately influenced morbidity and mortality $[5,6)$ Evidence of classification of diabetic coma was reported in 1886 by Professor Julius Dreschfeld. The hypothesis that microvascular disease underlies some major complications of diabetes (retinopathy, neuropathy, and nephropathy) was put forward in 1941 [6, 7]. The diabetic vascular complication [8] is a leading cause of end-stage renal failure, acquired blindness, a variety of neuropathies, and accelerated atherosclerosis, which could account for disabilities and high mortality rates in patients with diabetes [9].

Diabetes damages blood vessels, causing them to narrow and therefore restricting blood flow. Because blood vessels throughout the body are affected, people may have many complications of diabetes. These complications are responsible for most of the morbidity, hospitalizations, and 
International Journal of Pharma Research and Health Sciences, 2021; 9 (1): 3291-3295

even death. The chronic complications of diabetes mellitus occur as a result of several mechanisms, which result from the formation of advanced glycation end products, oxidative stress, and endothelial damage $[10,11]$ its leads to Micro and macrovascular complications; [12] such as retinopathy, neuropathy, nephropathy, foot disease, peripheral vascular disease, coronary artery disease, stroke, heart failure, etc. Data from the World Health Organization shows that men have twice as a higher risk of developing Coronary artery diseases (CAD) than women. Patients with diabetes also have an increased risk of cancers. They also have an increased risk of other disorders such as depression, cognitive decline, pancreatitis, etc. [13].

\section{METHODOLOGY}

\subsection{Study design, Study site, and Duration of study}

It is a prospective -observational study, carried out in the endocrinology department of public tertiary care hospitals in Guntur, for 9 months [14].

\subsection{Inclusion criteria}

1. All the patients are included between the age groups 3080 years who are diagnosed with Diabetes mellitus.

2. In our study, we include both males and females who are diagnosed with the microvascular complications of diabetes mellitus

\subsection{Exclusion criteria}

Patients who are not interested in participating in the study were excluded

\subsection{Data analysis and procedure}

Data that is collected and should be entered in the excel sheet. Demographic details of patients should are entered. Based on the Prospective and cross-sectional study, we should consider the inclusion and exclusion criteria for collecting the data. By this, we should analyze the data to know that how many patients were affected with vascular complications of diabetes mellitus like diabetic retinopathy, diabetic nephropathy, and diabetic neuropathy based on age, gender, BMI, duration of DM, type of DM, HbA1c. By this, we can know that which complication is more prevalent $[15$, $16]$.

\section{RESULTS AND DISCUSSION}

The morbidity and health care burden may increase based upon high prevalence and complications in diabetic patients. This present study evaluated the prevalence of vascular complications among diabetic patients attending a tertiary care hospital in Guntur, Andhra Pradesh.

\subsection{Demographic details of study subject}

Table 1: Demographic and clinical details of the study subject

\begin{tabular}{|l|l|}
\hline Characteristics of Study Sample & Frequency $(\mathbf{n = 2 1 5})$ \\
\hline Age (Years) & \\
$<35$ & $9(4.36 \%)$ \\
$35-50$ & $12(5.82 \%)$ \\
$51-65$ & $105(50.97 \%)$ \\
$66-80$ & $80(38.83 \%)$ \\
\hline
\end{tabular}

\begin{tabular}{|l|l|}
\hline$>80$ & $9(4.18 \%)$ \\
Gender & $122(56.74 \%)$ \\
Male & $93(43.25 \%)$ \\
Female & \\
Diseases Duration (Years) & $51(23.72 \%)$ \\
$0-5$ & $84(39.06 \%)$ \\
$6-10$ & $80(37.20 \%)$ \\
$>10$ & $28(13.02 \%)$ \\
BMI & $130(60.46 \%)$ \\
Normal weight $(<25)$ & $57(26.51 \%)$ \\
Overweight $(25-30)$ & \\
Obese $(>30)$ & $80(37.20 \%)$ \\
HbA1C & $135(62.79 \%)$ \\
Normal $(4-6 \%)$ & \\
Higher risk $(>6 \%)$ & \\
\hline
\end{tabular}

In our study may exploit the patient demographic and clinical information of type 2 diabetic patients. Such as Age, Gender, Duration, BMI, HbA1C. Out of 215 patients, males were 122 and females were 93 . Above $50 \%$ of patients were diagnosed within the age group of 51-65 years [17]. Almost $39 \%$ of patients were suffering from diabetes with duration of 5-10 years. About $61 \%$ of patients were having overweight based on BMI ranges and about $63 \%$ of patients were at high risk of $\mathrm{HbA1C}$ i.e., $>6 \%[18,19]$. The mean age was found to be 51-65(50.97\%). Similar results are observed in previous studies. Similarly in our study explore the Gender distribution of subjects, the high impact on 51-65 age groups, because diabetes may progressive by the aggregation factors like age and gender, BMI, HbA1C, etc. [20]. The tabular presentation was mentioned in table 1 .

\subsection{Age and Gender wise distribution of study subjects}

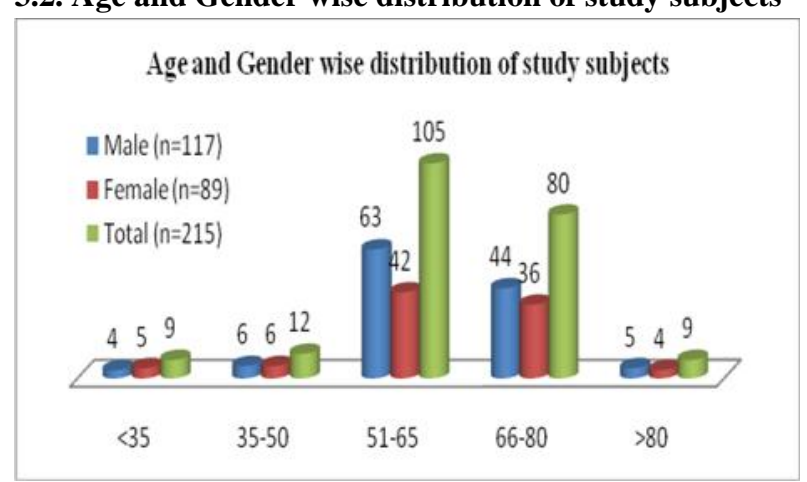

Fig 1: Age and Gender wise distribution of diabetic patients

This figure 1 shows age and gender-wise distribution in overall patients involved in the study. In our study males $(n=116)$ were prominent over females $(n=89)$. Out of 215 patients, over $48.83 \%$ were in the age group of 51-65 years followed by $37.20 \%, 4.18 \% \& 4.18 \%$ were in the age group of $>65,35-50,>80 \&<35$ years respectively. In our study may contribute to the unmodifiable risk factor for the development of complications in diabetic patients [21]. 
International Journal of Pharma Research and Health Sciences, 2021; 9 (1): 3291-3295

3.3. Description of comorbidities in patients involved in our study

Table 2: List of comorbidities

\begin{tabular}{|l|l|l|}
\hline S.NO & Co-morbidities & Frequency (\%) \\
\hline 1 & Hypertension & $112(52.09 \%)$ \\
2 & Hypertension +Hypothyroidism & $34(15.81 \%)$ \\
3 & Hypertension +Hypothyroidism and Asthma & $10(4.65 \%)$ \\
4 & Hypertension +Chronic Liver Disease & $7(3.25 \%)$ \\
5 & Hypertension+ Gastroenteritis & $5(2.32 \%)$ \\
6 & Hypertension +Urinary Tract Infection & $3(1.39 \%)$ \\
7 & None & $44(20.46 \%)$ \\
\hline
\end{tabular}

In diseases, progression is mainly supported with multiple associated conditions that may be resulting in the development of risk of complications. This table 2 shows, list of comorbidities present in the patients involved in our study. Out of all comorbidities, it was found that hypertension $112(52.09 \%)$ followed by $34(15.81 \%)$, $10(4.65 \%), 7(3.25 \%), 5(2.32 \%) \& 3(1.39 \%)$ hypertension along with other comorbidities. Similar results were noticed in other potential studies $[22,23]$

3.4. Types of diabetic vascular complications

Table 3: Different types of diabetic vascular complications

\begin{tabular}{|l|l|l|}
\hline No of the study subjects & $\begin{array}{l}\text { Microvascular } \\
\text { complications }\end{array}$ & $\begin{array}{l}\text { Macrovascular } \\
\text { complications }\end{array}$ \\
\hline Single & $147(66.04 \%)$ & $135(62.79 \%)$ \\
\hline Combinational & $41(19.06 \%)$ & $50(23.25 \%)$ \\
\hline Total & $188(86.51 \%)$ & $185(86.05 \%)$ \\
\hline
\end{tabular}

This table 3 shows both micro and macrovascular complications in overall patients. Some patients are having only a single complication either micro or macro and some are having combinational i.e., more than one complication, and some others having no complications. A single complication was mostly identified than the combinational type [24]. Out of all 215 patients, 188 micro and 185 macro complications were identified. Out of microvascular complications, 147 were single complications and 41 were combinational. Out of 185 macrovascular complications, 135 were single complications and 50 were combinational [25].

3.5. Gender wise distribution of diabetic vascular complications

Table 4: Gender Wise Distribution of Diabetic Vascular Complications

\begin{tabular}{|l|l|l|l|l|}
\hline $\begin{array}{l}\text { Gender wise } \\
\text { distribution }\end{array}$ & With & Without & With & Without \\
\hline Male & $108(50.23 \%)$ & $9(4.18 \%)$ & $106(49.30 \%)$ & $11(4.65 \%)$ \\
\hline Female & $80(37.20 \%)$ & $9(4.18 \%)$ & $79(36.74 \%)$ & $10(4.65 \%)$ \\
\hline
\end{tabular}

In general diabetic patients may have the risk for development of complications based on concurrent diseases and risk factors, in our study also reveals that gender-wise distribution in both micro and macrovascular complications. Out of all 215 patients, 108(50.23\%) male and 80(37.20\%) female with microvascular complications, 106(49.30\%) male and $79(36.74 \%)$ female with microvascular complications (table 4) [21, 22].
Table 5: Gender Wise Distribution of Micro-Vascular Complications

\begin{tabular}{|l|l|l|l|}
\hline $\begin{array}{l}\text { Micro-vascular } \\
\text { complications }\end{array}$ & Male (n=108) & Female (n=80) & Total (n=188) \\
\hline Retinopathy & 16 & 15 & 31 \\
\hline Neuropathy & 32 & 21 & 53 \\
\hline Nephropathy & 38 & 25 & 63 \\
\hline $\begin{array}{l}\text { Neuropathy } \\
\text { Nephropathy }\end{array}$ & 10 & 10 & 20 \\
\hline Nephropathy \&Retinopathy & 5 & 0 & 5 \\
\hline Neuropathy \& Retinopathy & 4 & 5 & 9 \\
\hline $\begin{array}{l}\text { Retinopathy, Neuropathy \& } \\
\text { Nephropathy }\end{array}$ & & 4 & 7 \\
\hline
\end{tabular}

This table 5 shows the gender-wise distribution of microvascular complications present in the patients involved in our study. Out of all 215 patients, microvascular complications, nephropathy $(n=63)$ was high followed by neuropathy $(n=53)$; retinopathy $(n=31)$, and males $(n=108)$ were more prone than of females $(n=80)$.based upon the condition that may lead to the respective complication in patients, the majority of patients may experience kidneyrelated abnormalities combined with supported by enhancing markers [23, 24].

3.6. Gender wise distribution of macro-vascular complications

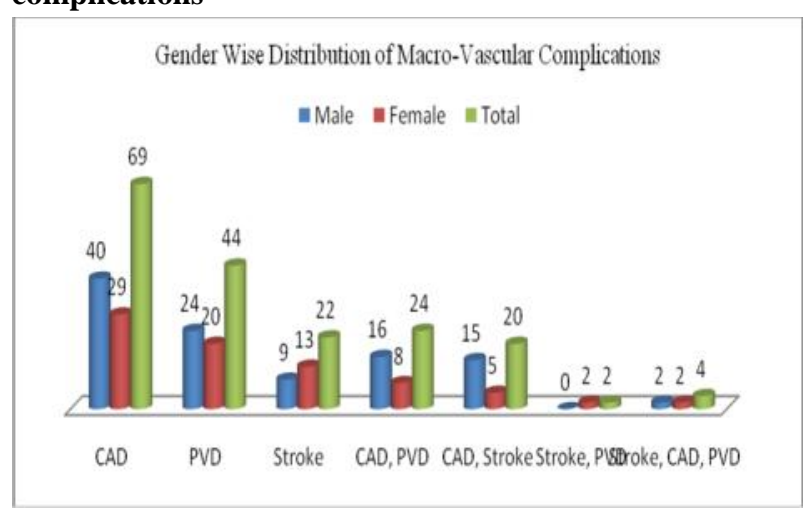

Fig 2: Gender wise distribution of macrovascular complications

This figure 2 shows the gender-wise distribution of macrovascular complications. Out of 185 macrovascular complications, majority were $\operatorname{CAD}(n=69)$; followed by PVD $(n=44)$, Stroke $(n=22)$ and males $(n=106)$ were prone than that of females $(n=79)$. Many studies to contribute to diabetes may increase the microvascular complication related to cardiovascular diseases [25, 26].

\section{Utilization of antidiabetic therapy}

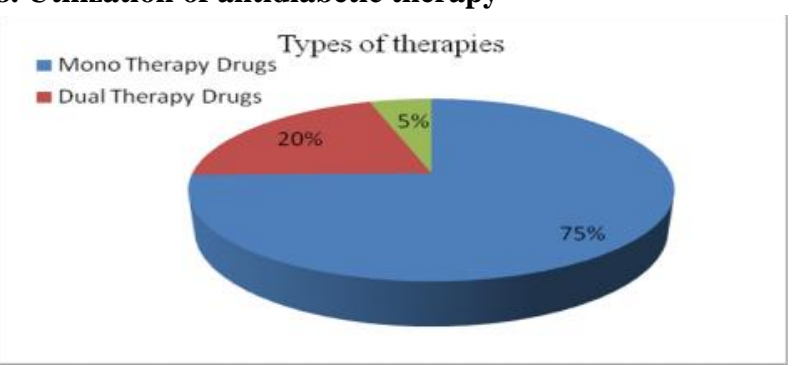

Fig 3: Utilization of antidiabetic therapy 
International Journal of Pharma Research and Health Sciences, 2021; 9 (1): 3291-3295

This shows about types of oral hypoglycemics agents used i.e., either Monotherapy or Dual therapy, or Triple therapy. Monotherapy 106 (49.30\%) and dual therapy 29 (13.48\%). Triple therapy 7 (3.25\%) usage was less when compared to mono and dual therapy [27].

Table 6: Overall utilization pattern of drugs

\begin{tabular}{|l|l|}
\hline Drug & Frequency(\%) \\
\hline Anti-Diabetic & $395(35.9 \%)$ \\
\hline Anti-Hypertensive & $157(14.2 \%)$ \\
\hline Anti-Platelets & $97(8.82 \%)$ \\
\hline Analgesics & $103(9.37 \%)$ \\
\hline GI drugs & $115(10.46 \%)$ \\
\hline Vitamins \& Minerals & $91(8.28 \%)$ \\
\hline Antibiotics & $106(9.91 \%)$ \\
\hline Others (HT) & $35(3.18 \%)$ \\
\hline TOTAL & 1099 \\
\hline
\end{tabular}

Anti-diabetic drugs accounted for almost $36 \%$ of the prescribed drugs followed by anti-hypertensive medications, which might be due to the higher prevalence of hypertension (14.2\%) among diabetic patients. The utilization of antiplatelet drugs and analgesics was $8 \%$ and $9 \%$ respectively. Furthermore, the utilization patterns of drugs used in the management of hypothyroidism were $3.18 \%$, vitamins and minerals $8 \%$, antibiotics $10 \%$, gastrointestinal drugs $10.5 \%$ and others $3.18 \%$ [28].

\section{CONCLUSION}

Among the vascular complications, microvascular complications were major in our study that was observed in almost 90 to $100 \%$ of neurological and macrovascular complications. Elevation of HbA1c levels was found to have a significant correlation with the expansion of neuropathy in patients with type 2 diabetes. The complication of neuropathy typically goes asymptomatic, unseen, and under diagnosed. Hence, it is more essential to await and to find the related complications. Monitoring and controlling the HbA1c levels are the most vital part of decreasing the complications and disease progression. Early detection and good glycemic control will help in preventing the mortality and morbidity-related risks among the diabetic population.

\section{REFERENCES}

1. Lakhtakia R. The history of diabetes mellitus. Sultan Qaboos Univ Med J 2013; 13: 368.

2. Shetty P. Public health: India's diabetes time bomb. Nature 2012; 485: S14-6.

3. Bertoldi AD, Kanavos P, França GV, Carraro A, Tejada CA, Hallal PC, et al. Epidemiology, management, complications and costs associated with type 2 diabetes in Brazil: a comprehensive literature review. Glob Health 2013; 9:1-2.

4. Deshpande AD, Harris-Hayes M, Schootman M. Epidemiology of diabetes and diabetes-related complications. Phys Ther 2008; 88: 1254-64.
5. Whiting DR, Guariguata L, Weil C, Shaw J. IDF diabetes atlas: global estimates of the prevalence of diabetes for 2011 and 2030. Diabetes Res Clin Pract 2011; 94: 311-21.

6. Ali A, Iqbal F, Taj A, Iqbal Z, Amin MJ, Iqbal QZ. Prevalence of microvascular complications in newly diagnosed patients with type 2 diabetes. PaK J Med Sci 2013; 29: 899.

7. Zaker A, Swamy TN. A Prospective Study To Investigate Diabetes mellitus Related Complications In Patients Of A South Indian Tertiary Care Hospital, Baptist Hospital, Bangalore. International Journal of Innovative Pharmaceutical Sciences and Research 2016; 4: 1133-9.

8. Wild S, Roglic G, Green A, Sicree R, King H. Global prevalence of diabetes: estimates for the year 2000 and projections for 2030. Diabetes Care 2004; 27: 1047-53.

9. Dreschfeld J. The Bradshawe Lecture on Diabetic Coma, Br Med J 1886; 2: 358-63.

10. Papatheodorou K, Banach M, Bekiari E, Rizzo M, Edmonds M. Complications of Diabetes 2017. J Diabetes Res 2018; 1-4.

11. Worku D, Hamza L, Woldemichael K. Patterns of diabetic complications at Jimma University Specialized Hospital, Southwest Ethiopia. Ethiop J Health Sci 2010; 20: 33-9.

12. Khazai MH, Khazai B, Zargaran Z, Moosavi Z, Zand FK. Diabetic complications and risk factors in recently diagnosed type II diabetes: a case-control study. ARYA Atherosclerosis 2010; 2.

13. Fowler MJ. Microvascular and macrovascular complications of diabetes. Clinical diabetes 2011; 29:116-22.

14. Forbes JM, Cooper ME. Mechanisms of diabetic complications. Physiological reviews 2013; 93:137-88.

15. Unnikrishnan R, Anjana RM, Mohan V. Diabetes mellitus and its complications in India. Nat Rev Endocrinol 2016; 12: 357-70.

16. Mantro O, Mohanan J. A study of clinical profile and complications in patients with type 2 diabetes mellitus in a tertiary care center. Int J Adv Med 2019; 6: 279-83.

17. Zuhara NVF, Banu AT, Chokli N. Gender wise prevalence of comorbidities and medication adherence among type 2 diabetics in Malappuram. Int J Pharm Sci Res 2019; 10: 4787-93.

18. Agrawal N, Agrawal MK, Kumari T, Kumar S. Association of body mass index and blood glucose level in Jharkhand. International Journal of Contemporary Medical Research 2017; 4: 1633-36.

19. Haghighatpanah M, Thunga G, Khare S, Mallayasamy S. Correlation of glycosylated hemoglobin levels with fasting and postprandial glucose in South Indian Type 2 diabetic patients. Int J Pharm Pharm Sci 2016; 8: 285-8. 
International Journal of Pharma Research and Health Sciences, 2021; 9 (1): 3291-3295

20. Young EE, Okaforc N, Okwara CC. Diabetes mellitus, associated co-morbidities, and complications - A review, Journal of Medicine and Medical Sciences 2016; 7: 047-55.

21. Jelinek HF, Osman WM, Khandoker AH, Khalaf K, Lee $\mathrm{S}$, Almahmeed W, et al. Clinical profiles, comorbidities and complications of type 2 diabetes mellitus in patients from United Arab Emirates. BMJ Open Diabetes Res Care 2017; 5: 1-9.

22. Al-Maskari F, El-Sadig M. Prevalence of diabetic retinopathy in the United Arab Emirates: a crosssectional survey, BMC Ophthalmol 2007; 7: 1-8.

23. Pradeepa R, Mohan V. Prevalence of type 2 diabetes and its complications in India and economic costs to the nation. Eur J Clin Nutr. 2017; 71: 816-24.

24. Li J, Chattopadhyay K, Xu M, Chen Y, Hu F, Chu J, et al. Prevalence and associated factors of vascular complications among inpatients with type 2 diabetes: A retrospective database study at a tertiary care department, Ningbo, China. PLoS ONE 2020; 15: 2-14.

25. Raveendra babu K, Deepika Reddy B, Bheemamma P, Vamshi Krishna E, Chinna Eswaraiah M., Prevalence of microvascular complications of diabetes mellitus in tertiary care hospital. International Journal of Research in Pharmaceutical Sciences 2020; 11: 2049-55.

26. Abdi SH, Churi S, Ravi Kumar YS. Study of drug utilization pattern of antihyperglycemic agents in a South Indian tertiary care teaching hospital. Indian J Pharmacol 2012; 44: 210-4.

27. Khan M, Ullah R, Khan A, Khan S, Riaz M. Assessment of Prescriptions in the Endocrinology Department of a Tertiary Care Hospital in Pakistan Using World Health Organization Guidelines. Advances in preventive medicine 2020.

28. Alex SM, Sreelekshmi BS, Smitha S, Jiji KN, Menon AS, Uma Devi P. Drug utilization pattern of antidiabetic drugs among diabetic outpatients in a tertiary care hospital. Asian J Pharm Clin Res 2015; 8: 144-6.

CONFLICT OF INTEREST: The authors declare no conflict of interest, financial or otherwise.

SOURCE OF FUNDING: None.

AVAILABILITY OF DATA AND MATERIALS: Not applicable.

CONSENT FOR PUBLICATION: Not applicable.

ETHICS APPROVAL AND CONSENT TO PARTICIPATE: PD0010/IRB/NRML/2019-20. 